\title{
MISCONSTRUING AGENCY: ISSUES RELATED TO FREE WILL AND DETERMINISM
}

\author{
Shirley Matile Ogletree
}

Texas State University, Texas, USA

Received 2014-01-17; Revised 2014-01-23; Accepted 2014-02-15

\begin{abstract}
Agency (related to intentionality and the importance of choices) and free will ("could have done otherwise") have been confounded in previous psychological research, with assessments and manipulations of free will often including items related to agency. Therefore, correlates previously associated with free will may, to some extent, be based on agentic assumptions. In this study 152 college students from a central Texas university, participating in on-line research using Qualtrics, read one of four essays that separately manipulated agency and free will in a $2 \times 2$ design. After reading the essays, participants completed assessments of blame, agency and free will. As hypothesized, the free will measure, but not the agency measure, significantly predicted blame, $\mathrm{F}(1,128)=4.09, \mathrm{p}<0.05$. Although the manipulations were not successful in impacting the levels of agency or free will, the potential for experimentally manipulating the factors independently was illustrated. Free will and agency were moderately correlated, $r(132)=0.55$, $\mathrm{p}<0.001$, indicating that, in the understanding of laypersons, the two concepts are to some extent connected and likely related to low levels of deterministic beliefs in the U.S. culture.
\end{abstract}

Keywords: Blame, Determinism, Free Will, Agency

\section{INTRODUCTION}

Free will is often confounded with agency. For example, Rakos et al. (2008) described determinism and libertarian free will on opposite ends of a onedimensional continuum varying in degree of agency. Similarly, Baumeister et al. (2009) have included sentences like "I demonstrate my free will every day when I make decisions", in manipulations of free will/determinism.

Bandura (2006) defined agency as intentionally influencing "one's functioning and life circumstances" (p. 164). His four core properties of human agency were (1) intentionality, (2) forethought, (3) self-reactiveness (related to self-regulation) and (4) self-reflectivenss. Although agency from this perspective does include deliberation and contemplation, no specification is made related to free will or determinism.

Free will and determinism have been defined a variety of ways (Ayer, 1954; Dennett, 1984; 2005; Hodgson, 2005; Kane, 2002; Stace, 1952; Wegner,
2004). However, one essential part of the argument relates to the nature of human choice from the perspective that the person "could have done otherwise". If will is to be "free", the individual who is choosing needs to be able to not only choose among alternatives, but in addition have a variety of different possible outcomes. The determinist argues that, given genetic and environmental determinants as well as their various interactions, only one outcome is possible in any given situation. However, this does not negate the active, choosing process.

In other words, the individual can, during a deliberative, decision-making process, consider multiple outcomes. Moreover, deliberately considering pros and cons of different choices does not preclude only one outcome ultimately being possible, the deterministic perspective. Even such factors as the length of deliberation and the options considered are determined, a function of one's past/present environment, one's genes and the interactions among these influences. In other words, the phenomenological process of choosing does 
not negate only one outcome being possible. Agency here is defined as believing that one makes choices and that those choices are important while free will refers simply to multiple outcomes, versus only one, being possible when an individual chooses.

If "free" will is something outside of or in addition to the environmental and genetic determinants of behavior and independent of neural activity, what is it? Wegner (2004), in this vein, asked where this "free willer" might reside in the brain and what leads to any related choices that are independent of genetic and environmental determinants. The argument is not that we don't have "will", but that the will is not "free"; rather it is determined by genetic and environmental influences.

What are the implications of believing in free will or determinism? Baumeister and colleagues reported that exposure to a deterministic perspective decreased the likelihood of helping (Baumeister et al., 2009) and increased the likelihood of cheating (Vohs and Schooler, 2008). Believing in free will has also been positively related to ratings of employee performance (Stillman et al., 2010).

Others have argued that a stronger belief in free will relates to more judgmental attitudes towards others. Rakos et al. (2008) found that both high school and college students associated retribution with free will. Free will scores have also been associated with believing in a just world, authoritarianism and punitiveness (Carey and Paulhus, 2013). Believing that a person "could have done otherwise" may lead to a greater likelihood to blame others for their misfortunes.

However, the measures and manipulations of free will/determinism have confounded free will with agency and moral responsibility (Ogletree, 2013). One can have "will" or "agency", without that choice being free. From a theoretical perspective, agency and free will should be regarded as separate constructs. The purpose of the current research was to separate the dimensions of agency and free will/determinism by having students read paragraphs related to the importance of choice as well as the number of outcomes. Exposure to a paragraph emphasizing the importance of choice, versus minimizing the importance of choice, should increase a measure of agency but should not impact free will, if the assessment of free will does not include confounded items related to agency and moral responsibility. Similarly, paragraphs related to the number of possible outcomes, presented independently of information about the importance of choice, should impact free will/determinism measures but not a measure of agency.
Moreover, blaming others for the misfortunes that befall them should be related both to a measure of free will and also to the manipulation emphasizing multiple outcomes being possible in any given situation.

The hypotheses, then, were as follows:

- $\quad$ Reading a paragraph describing each choice as very important, versus each choice as not that important, will increase agency but not free will

- Reading a paragraph describing only one possible outcome, versus multiple outcomes, will decrease a belief in free will, but not affect agency

- Emphasizing multiple options being possible will increase victim blaming

- A free will measure will be positively related to blame as well

\section{MATERIALS AND METHODS}

\subsection{Participants}

Students (35 males, 117 females) in a Psychology of Human Sexuality class Fall, 2012 at a central Texas university were given an extra credit option of participating in an on-line study using Qualtrics. Although the primary indicated ethnicity was Caucasian $(53 \%)$, over a quarter of the participants (27\%) were Hispanic, $10 \%$ were African-American, $4 \%$ were Asian and 5\% indicated "other". Most of the participants were middle class $(52 \%)$, lower-middle class $(22 \%)$, or upper-middle class $(19 \%)$.

\subsection{Materials and Procedure}

Participants at their own convenience logged on to a Qualtrics site, gave consent for research participation and then began the survey. After answering five demographic questions, participants read one of four randomized essays, answered four comprehension questions, indicated their agreement with the essay, read six vignettes (Savani et al., 2011) with a related "blame" question for each, answered a nine-question "agency" assessment as well as a six-item "free-will" measure and completed two final items asking participants to rate how conservative-liberal and how religious they were.

The four essays were entitled "The Natural World and Human Choice" and manipulated two dimensions: (1) the number of possible outcomes of any decision-making process (one, multiple outcomes) and (2) the importance of choosing (each decision very important, each decision not that important). Students were asked to carefully read 
each essay twice because they would not be able to go back when answering comprehension questions.

The first paragraph used in all four essays was 129 words long and described common assumptions about the natural world such as "if all factors are controlled, the outcome will always be the same". A heading "How do humans fit into the natural world?" was used before the second paragraph (64 words long) which was also the same in all manipulations. Following this paragraph another "heading" asked students to think about choices they have made and how they make choices. The next three paragraphs (either 208 or 209 words long) involved the manipulations. In the "one outcome" conditions, the manipulation included the following:

\begin{abstract}
Many people, including famous scholars, believe our choices are determined by our genes, our past environment and our current situation or environment. Ultimately, as we go through a decision-making process, only one outcome is possible, given that the person we are is the sum total of our biology and our past experiences.
\end{abstract}

In the "multi-outcome" option participants read:

Many people, including famous scholars, believe that human decisions are based on having the free will to choose from multiple options that can affect our future. We have the freedom to choose. Ultimately it is up to us to choose from the options available to us and make the right decision.

The importance of choice was manipulated with the following wording in the "choice-very important" condition:

The decision-making process itself, though, is very important because, with each choice, we are in essence creating the person we are becoming. The direction we take will, in turn, lead us to have some experiences, but not others.

The wording of the "choice-not important" manipulation included the following:

Because we make many choices in our lives, each individual decision is not that important. If the outcome of our choices are not what we want today, we can modify, change our direction, tomorrow or in the future.
The last paragraph included an underlined statement about "the bottom line" from this perspective, indicating that a choice has one outcome or multiple possible outcomes and that each choice is very important or not that important.

Four questions were then used to assess comprehension. The first question asked participants about the importance of choice, according to the essay just read. The third question asked them about the number of outcomes, again according to the essay. The second and fourth questions asked students two content questions about what was mentioned (Mars rover, building bridges and skyscrapers).

The vignettes used to assess blame were from Savani et al. (2011) fourth experiment, available in the supplemental on-line material. One of the two available vignettes (varied by the victim's socioeconomic status) for each of the six scenarios was chosen, using the described 7-point scale with "not at all" and "very much" as the endpoints for rating the degree of blame ascribed to the person in each of the six vignettes. These scores were then totaled for a "blame" score.

The assessment of agency included three items from the Rakos et al. (2008) Free will and Determinism ScalePersonal Agency factor ("I am in charge of the decisions I make", "I decide what action to take in a particular situation", and "I am in charge of my actions even when life's circumstances are difficult",); three item's from Stillman et al. (2010) career performance measure ("I will be a success in the workplace", "Whoever hires me will regret it"-reversed scored and "Career success is important to me".); and three items I wrote about succeeding at school ("In general my success at school doesn't seem very related to my decisions and effort"-reversed scored, "Even when my classes are hard, I am successful because of my planning and willingness to work hard" and "I do well as a student because of the choices I make"). Cronbach's alpha for these nine items was 0.80 in our sample.

Finally, participants completed items used in previous research to manipulate or measure free will, including two from Baumeister et al. (2009) determinism/free will manipulation ("I am able to override the genetic and environmental factors that sometimes influence my behaviors", "All behavior is determined by brain activity, which in turn is determined by a combination of environmental and genetic factors"-reversed scored), three from Stroessner and Green (1990) Free Will-Determinism Scale-Libertarianism Factor ("I will have free will all of my life", "I have free will in life, regardless of group expectations or pressures"; "I am free to make choices in 
my life regardless of social conditions") and one item ("I have free will even when my choices are limited by external circumstances") that loaded on the free will factor from the Rakos et al. (2008). A 5-point scale, ranging from "strongly disagree" to "strongly agree" was used for all of the agency and free will items. After removing the reversed scored item from the scale, the remaining five free-will items had an alpha of 0.82 ; the reliability was 0.67 with all six-times included. The five-item measure was used in further analyses.

Finally, two items asked participants to assess how liberal-conservative (ranging from "extremely conservative" to "extremely liberal") and how religious (ranging from ""not at all religious" to "very religious") they were. Seven-point scales were used for these two items.

\section{RESULTS}

\subsection{Preliminary analyses}

To check how carefully students read the paragraphs, the four comprehension questions were examined for accuracy. As can be seen from Table 1, a number of participants, particularly in the "one outcome, choice not that important" condition, did not carefully read or comprehend the essays.

\subsection{Primary analyses}

To examine the effect of the essay manipulation, two 2-way analyses of variance were performed on "agency", and "free will", with choice (important/not that important) and number of outcomes (one, multiple) as the independent variables. None of the main or interaction effects were significant in these analyses. In addition, agreement with the essays did not vary by these factors.

A forward regression was performed on "blame"; predictors were number of outcomes, importance of choice, free will, agency, the conservative/liberal rating and rated religiosity. Free will was the only variable to enter the equation, $\mathrm{F}(1,128)=4.09, \mathrm{p}<0.05$, adjusted $\mathrm{r}^{2}$ $=0.02, \beta=0.18$.

Because agency was somewhat skewed and bunched together (skewness statistic $=-1.14$; kurtosis $=2.26$ ), a median test was also performed comparing those who read the "choice important" and the "choice not important" groups. The comparison was not significant.

Spearman rho correlations among free will, agency, liberalism and religiosity were also examined and are given in Table 2.

\subsection{Additional analyses}

Because so many participants did not carefully read or comprehend the intent of the essays on The Natural World and Human Choice, some additional analyses were performed after excluding participants who missed the two comprehension questions related to the number of outcomes and the importance of choice. However, the two-way ANOVA's for agency and free will were again not significant (but only six participants remained in the one outcome-choice not important condition); moreover, the two "choice important/not important" groups both had a median of 39 on agency. However, a significant main effect of number of outcomes on the degree of agreement with the essay was found $F(1,62)=4.47$, $\mathrm{p}<0.05$; the mean for one outcome was 3.14 , compared to 3.71 for multiple outcomes, indicating more agreement with the multiple outcomes essay.

Table 1. Number of comprehension questions answered correctly by condition and question

\begin{tabular}{lllllr}
\hline Condition $(\mathrm{N})^{\mathrm{a}}$ & Important/Not & Mars rover & \#--Outcomes & Build bridges & All correct \\
\hline C-I, O-1 (35) & 32 & 26 & 23 & 27 & 18 \\
C-NI, O-1 (33) & 9 & 17 & 11 & 13 & 1 \\
C-I, O-M (39) & 32 & 23 & 28 & 23 & 16 \\
C-NI, O--M (34) & 17 & 23 & 22 & 19 & 8
\end{tabular}

${ }^{\mathrm{a}} \mathrm{C}-\mathrm{I}$ and $\mathrm{C}-\mathrm{NI}$ refer to the choice important/not important manipulation; O-1 and O-M refer to the number of outcomes (one, or multiple)

Table 2. Spearman rho correlations among variables

\begin{tabular}{|c|c|c|c|c|c|}
\hline Variable & Blame & Agency & Free will & Liberal & Religious \\
\hline Blame & & 0.14 & $0.21 *$ & -0.10 & 0.09 \\
\hline Agency & & & $0.55 * * *$ & -0.02 & $0.28 * *$ \\
\hline Free will & & & & 0.11 & 0.03 \\
\hline Liberal & & & & & $-0.33 * * *$ \\
\hline
\end{tabular}

$* \mathrm{p}<0.05, * * \mathrm{p}<0.01, * * * \mathrm{p}<0.001$ 


\section{DISCUSSION}

In general the paragraph manipulations regarding the number of outcomes and the importance of choice were not successful in affecting ratings of free will or agency. Several explanations are possible, including the majority of the students not carefully reading/comprehending the essays and the brief manipulations not being sufficient to impact strongly held beliefs. According to Ogletree and Oberle (2008), only $15 \%$ of college students support a hard determinism perspective; similarly, Rakos et al. (2008) argued that-"a generalized libertarian belief in free will is the 'default' philosophy of most persons" (p.31). The brief argument offered in the "one outcome" manipulation was seemingly not effective in countering such a belief. Significant differences in free will were not found comparing those who read the oneoutcome versus the multiple outcomes versions of the essay and participants who answered related comprehension questions correctly agreed more with the multiple outcomes essay.

Agency may have experienced a ceiling effect ( skewness statistic $=-1.14$ ); the mean agency score was 38.74 (median of 39) out of a possible 45. The scores were also closely clustered (kurtosis $=2.26$ ). Even though the nine-item measure had acceptable reliability (0.80), the nature of the distribution may have negatively impacted finding any effects of the manipulation related to the importance of choosing. In addition, the manipulation may have been ineffective as the medians for both groups related to the importance of choice manipulation were the same.

The only hypothesis that was supported, in line with previous research (Carey and Paulhus, 2013; Rakos et al., 2008) was the association of blame with free will. Logically if we believe that individuals could have freely chosen to do otherwise, then they are more likely to be blamed than if they could not have done other than what they did. Smilansky (2005) has called determinism "the great eraser", having the effect of reducing individual guilt as well as judgmental attitudes towards others. Just as learning more about an individual's background can reduce blame (Ogletree and Archer, 2011), believing that others' behavior is a result of their genetic and environmental determinants may lead to greater tolerance and understanding.

In this sample agency and free will were moderately correlated. At least in the understanding of the layperson and as argued by others (Carey and Paulhus, 2013), people link agency with free will. This may be associated with a misunderstanding of determinism and a failure to distinguish between agency and free will may contribute to the rejection of a deterministic philosophy. Certainly we have the subjective experience of making choices, leading us to the conclusion that multiple outcomes are possible when in fact the ultimate choice we make is a function of our genetic heritage, our past experiences and the current situation.

\section{CONCLUSION}

Confusing agency with free will may be related to many people's reluctance to accept a scientific, deterministic perspective. Intentionally deliberating and choosing, with resulting consequences, does not preclude only one possible outcome in the decision-making process. From either a deterministic or free will perspective, we can view each decision, each choice, as forming the person we are becoming; we are creating ourselves. As in Escher (1983) print of two hands each drawing the other hand, in essence we are the artist of our own destiny with the choices that we make.

\section{REFERENCES}

Ayer, A.J., 1954. Philosophical Essays. 1st Edn., MacMillian, London, ISBN-10: 0313209022, pp: 289.

Bandura, A., 2006. Toward a psychology of human agency. Perspect. Psychol. Sci., 1: 164-180. DOI: 10.1111/j.1745-6916.2006.00011.x

Baumeister, R.F., E.J. Masicampo and C.N. DeWall, 2009. Prosocial benefits of feeling free: Disbelief in free will increases aggression and reduces helpfulness. Personality Soc. Psychol. Bull., 35: 260-268. DOI: 10.1177/0146167208327217

Carey, J.M. and D.L. Paulhus, 2013. Worldview implications of believing in free will and/or determinism: Politics, morality and punitiveness. J. Personality, 81: 130-141. DOI: 10.1111/j.14676494.2012.00799.x

Dennett, D.C., 1984. I could not have done otherwise-so what? J. Philosophy, 81: 553-565.

Dennett, D.C., 2005. Natural freedom. Metaphilosophy, 36: 449-459.

Escher, M.C., 1983. 29 Master Prints. 1st Edn., Harry N. Abrams, Inc. Publishers, New York, pp: 62.

Hodgson, D., 2005. A plain person's free will. J. Consciousness Stud., 12: 3-19.

Kane, R., 2002. Introduction: The Contours of Contemporary Free Will Debates. In: The Oxford Handbook of Free Will, Kane, R. (Ed.), Oxford University Press, Oxford, ISBN-10: 0195133366, pp: 3-41. 
Ogletree, S.M. and C.D. Oberle, 2008. The nature, common usage and implications of free will and determinism. Behav. Philosophy, 36: 97-111.

Ogletree, S.M. and R.L. Archer, 2011. Interpersonal judgments: Moral responsibility and blame. Eth. Behav., 21: 35-48. DOI: $10.1080 / 10508422.2011 .537569$.

Ogletree, S.M., 2013. Doing the right thing: Determinism, moral responsibility and agency. Int. J. Humanit. Soc. Sci., 3: 1-7.

Rakos, R.F., K.R. Laurene, S. Skala and S. Slane, 2008. Belief in free will: Measurement and conceptualization innovations. Behav. Soc. Iss., 17: 20-39. DOI: $10.5210 \% 2 F b s i . v 17 i 1.1929$

Savani, K., N.M. Stephens and H.R. Markus, 2011. Unanticipated interpersonal and societal consequences of choice: Victim blaming and reduced support for the public good. Psychol. Sci., 22: 795-802. DOI: $10.1177 / 0956797611407928$

Smilansky, S., 2005. Free will and respect for persons. Midwest Stud. Philosophy, 29: 248-261.
Stace, W.T., 1952. Religion and the Modern Mind. 1st Edn., Lippincott, pp: 285.

Stillman, T.F., R.F. Baumeister, K.D. Vohs, N.M. Lambert and F.D. Fincham et al., 2010. Personal philosophy and personnel achievement: Belief in free will predicts better job performance. Soc. Psychol. Person. Sci., 1: 43-50. DOI: 10.1177/1948550609351600

Stroessner, S.J. and C.W. Green, 1990. Effects of belief in free will or determinism on attitudes toward punishment and locus of control. J. Soc. Psychol., 130: 789-799.

Vohs, K.D. and J.W. Schooler, 2008. The value of believing in free will. Psychol. Sci., 19: 49-54. DOI: 10.1111/j.1467-9280.2008.02045.x

Wegner, D.M., 2004. Précis of the illusion of conscious will. Behav. Brain Sci., 27: 649-692. DOI: 10.1017/S0140525X04000159 